\title{
Effects of solar and geomagnetic activities on the sub-ionospheric very low frequency transmitter signals received by the DEMETER micro-satellite
}

\author{
Mohammed Yahia Boudjada ${ }^{1}$, Konrad Schwingenschuh ${ }^{1}$, Emad Al-Haddad ${ }^{2}$, Michel Parrot ${ }^{3}$, Patrick \\ H.M. Galopeau ${ }^{4}$, Bruno Besser ${ }^{1}$, Günter Stang1 ${ }^{5}$, Wolfgang Voller ${ }^{1}$
}

\author{
${ }^{1}$ Institut für Weltraumforschung der Österreichischen Akademie der Wissenschaften, Graz, Austria \\ ${ }^{2}$ Akademischer Lehrgang Software Engineering an der FH Campus 02, Graz, Austria \\ ${ }^{3}$ Laboratoire de Physique et Chimie de l'Environnement et de l'Espace, Université d'Orléans, CNRS, Orléans, France \\ ${ }^{4}$ Laboratoire Atmosphères, Milieux, Observations Spatiales, CNRS, IPSL, Guyancourt, France \\ ${ }^{5}$ Bundesamt für Eich- und Vermessungswesen, Vienna, Austria
}

\section{Article history}

Received July 15, 2011; accepted November 14, 2011.

Subject classification:

Earthquakes prediction, Ionospheric disturbances, Solar and geomagnetic activities, Pre-seismic electromagnetic emissions.

\section{ABSTRACT}

In the framework of seismic precursor electromagnetic investigations, we analyzed the very low frequency (VLF) amplitude signals recorded by the Instrument Champ Electrique (ICE) experiment on board the DEMETER micro-satellite. The sun-synchronous orbits of the micro-satellite allowed us to cover an invariant latitude of between $-65^{\circ}$ and $+65^{\circ}$ in a time interval of about $40 \mathrm{~min}$. We considered four transmitter signals emitted by stations in Europe (France, FTU, $18.3 \mathrm{kHz}$; Germany, DFY, $16.58 \mathrm{kHz}$ ), Asia (Japan, JP, $17.8 \mathrm{kHz}$ ) and Australia (Australia, NWC, $19.8 \mathrm{kHz}$ ). We studied the variations of these VLF signals, taking into consideration: the signal-to-noise ratio, sunspots, and the geomagnetic activity. We show that the degree of correlation in periods of high geomagnetic and solar activities is, on average, about $40 \%$. Such effects can be fully neglected in the period of weak activity. We also find that the solar activity can have a more important effect on the VLF transmitter signal than the geomagnetic activity. Our data are combined with models where the coupling between the lithosphere, atmosphere and ionosphere is essential to explain how ionospheric disturbances scatter the VLF transmitter signal.

\section{Introduction}

Electromagnetic phenomena over a wide frequency range have been recognized as precursors to earthquakes. Precursor emissions have been found to cover a large frequency spectrum, as reported by several studies: ultra-low frequency (ULF) [Fraser-Smith et al. 1990, Molchanov et al. 1992, Hayakawa et al. 1996], extremely low frequency/ very low frequency (ELF/VLF) [Gokhberg et al. 1982, Parrot and Lefeuvre 1985], low frequency (LF) [Biagi and Hayakawa 2002], and high frequency (HF) [Warwick et al. 1982]. These first investigations were supported by laboratory experiments, where the stress of the rock was shown to release free electrons and electric charges, as reviewed by Parrot [1995], Hayakawa and Molchanov [2002], and Molchanov and Hayakawa [2008].

1.1. Very low frequency transmitter signals over seismic regions

VLF transmitters are primarily devoted to navigation and communication with military submarines. Most of the energy radiated by such transmitters is trapped between the ground and the lower ionosphere, which forms the Earth-ionosphere waveguide. The remote sensing of the ionosphere using different techniques, like the ground vertical sounding [Liperovskaya et al. 2008, Liperovsky 2008a, b, Pulinets et al. 2002], has shown anomalies in the electron density of the ionosphere above seismic regions. The complementarity of ground-based and space observations allows us local and spatial cover of earthquake regions.

The DEMETER micro-satellite was devoted to the study of electromagnetic pre-seismic emissions using a series of experiments that provide a more complete view of these phenomena [Parrot et al. 2006]. The use of electric and magnetic field measurements on board the DEMETER microsatellite have demonstrated that the intensity levels of transmitter signals decrease a few days before a seismic event occurrence [Molchanov et al. 2006]. Molchanov et al. [2006] estimated the variations in the VLF signals emitted by transmitters in Australia (code: NWC), France (code: FTU), Germany (code: DFY), and Japan (code: JP). These showed drops in their VLF signals a few days before the occurrence of large earthquakes (magnitudes >5.5) in Europe and in Asia. Later, several investigations [Rozhnoi et al. 2007, Boudjada et al. 2008, Muto et al. 2008, Slominska et al. 2008] confirmed 
this drop in VLF intensity. It is important to note that the decrease in the VLF intensity also concerns the natural whistler emissions, as reported by Boudjada et al. [2010] for the L'Aquila earthquake (April 6, 2009). Hence, it was seen that the signal of the DFY transmitter was 'damped' from 5 days before to a minimum of one day before the earthquake. Also, the VLF whistler emission, which is generated mainly in the magnetosphere, decreased from 7 days before and attained a minimum on the day of the L'Aquila seismic event. The disturbance of both of these VLF signals (i.e. transmitter and whistler emission) might largely be due to the earthquake preparation zone. This indicates that not only the lower part of the ionosphere is disturbed, but also the higher part, at the altitudes of the DEMETER satellite.

1.2. Effects of solar and geomagnetic activities on the Earth ionosphere

The influence of geomagnetic activity, and also solar activity, cannot be neglected in studies of pre-seismic anomalies related to the Earth ionosphere. Several parameters, like the Kp-index, Ap-index, Dst-index and the sunspot numbers, are taken into consideration to separate ionospheric anomalies that are associated with earthquakes from others that are principally linked to geomagnetic activity. In general, the selected earthquake events are analyzed during periods of relatively quiet geomagnetic activity.

Rozhnoi et al. [2007] suggested that the effects of geomagnetic activity (described by the Dst-index) can be neglected, because such effects were absent in VLF transmitter signals in the Hawaii islands (code NPM) and in Australia (code NWC) for Japanese seismic events (November to December 2004, August 2005). Boudjada et al. (2008, 2010) considered the Kp-index, and showed that the geomagnetic activity was weak for the European earthquakes that occurred in Italy (December 2004, April 2009). However, the general behavior of the geomagnetic activity is similar to the VLF intensity variations.

\section{Data investigation}

In the following subsections, we describe the steps in the analysis of the relationships between the solar/geomagnetic activities and the VLF transmitter signals. First, we consider the VLF observations recorded by the Instrument Champ Electrique (ICE) experiment above the VLF transmitter ground-based stations. After this, we estimate the signal-tonoise ratio, and we fill the gaps in the data by using the interpolation technique. This allows us to give an averaged estimation of the VLF intensity and the corresponding standard deviation. Then we select specific periods, between August 8, 2004, and December 31, 2006, when the sunspot number, or the daily Ap-index, was large. In the last step, we proceed to the correlation of the solar/geomagnetic activities and the VLF averaged signals.

\subsection{Methods of analysis}

The ICE experiment [Berthelier et al. 2006] provides a survey from ULF to HF for each half-orbit. The survey consists of a dynamic spectrum that shows the intensity level variations versus the frequency ranges and the observation times. Each dynamic spectrum comprises 980 sequential spectra, each of which consists of 1024 frequency channels. The high spectral resolution of the experiment (pixel size,

\begin{tabular}{|c|c|c|c|c|}
\hline $\begin{array}{l}\text { Transmitter } \\
\text { code }\end{array}$ & $\begin{array}{l}\text { Frequency } \\
\quad(\mathrm{kHz})\end{array}$ & $\begin{array}{l}\text { Latitude } \\
\left({ }^{\circ}\right)\end{array}$ & $\begin{array}{l}\text { Longitude } \\
\left({ }^{\circ}\right)\end{array}$ & $\begin{array}{c}\text { ICE: Closest frequency } \\
(\mathrm{kHz})\end{array}$ \\
\hline NWC & 19.8 & -21.5 & 114 & 19.8047 \\
\hline FTU & 18.3 & +46.4 & 1.05 & 18.3008 \\
\hline $\mathrm{JP}$ & 17.8 & +32.0 & 130 & 17.7930 \\
\hline DFY & 16.56 & +52.5 & 13.0 & 16.5625 \\
\hline
\end{tabular}

Table 1. Main features of the VLF stations and closest frequencies to the transmitter.
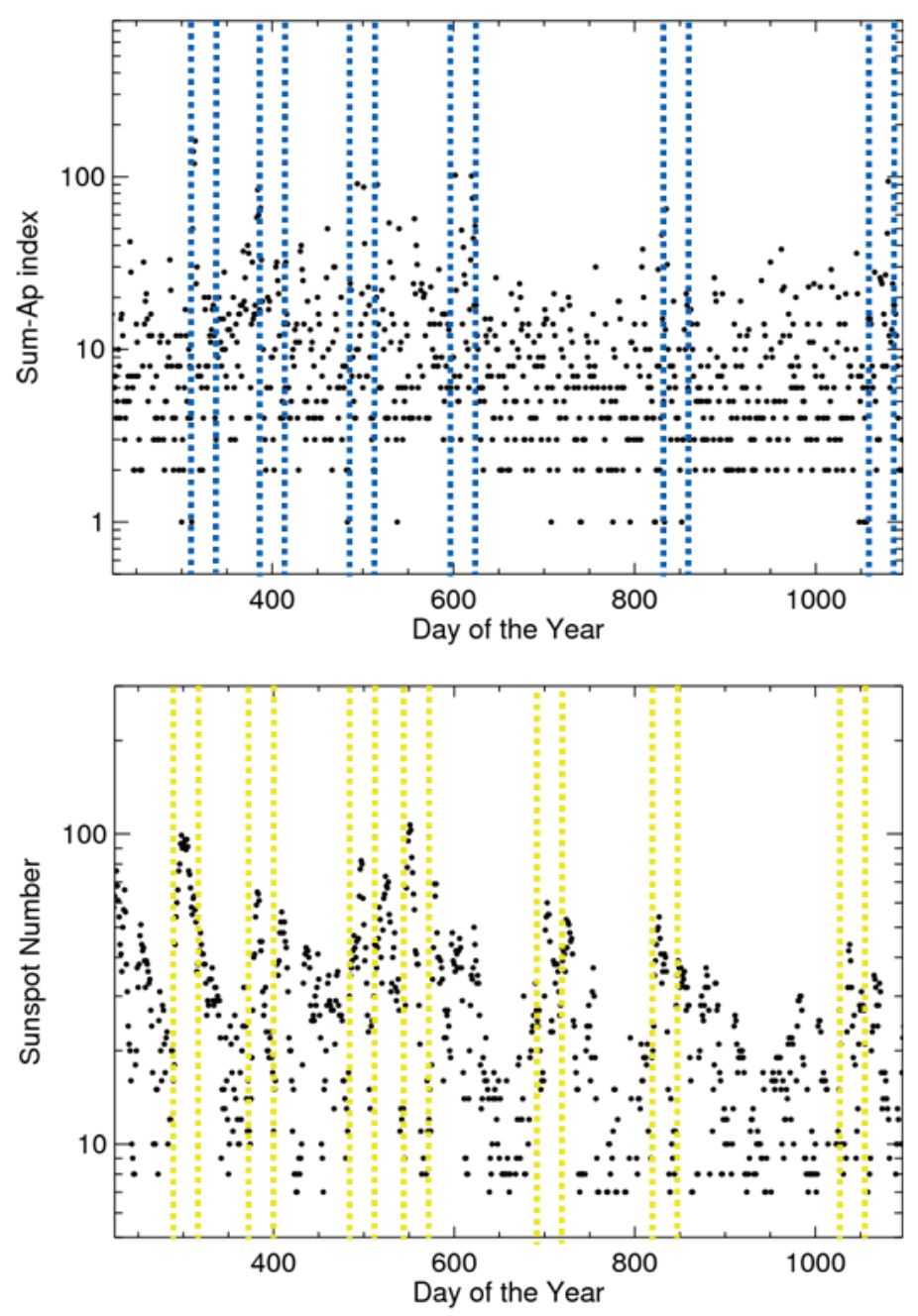

Figure 1. Daily Ap-index (upper panel) and sunspot number (lower panel) variations versus DOY (first day: January 1, 2004). The period investigated starts from August 8, 2004 (DOY 221) and goes to December 31, 2006 (DOY 1098). The blue and yellow vertical lines indicate the periods of high geomagnetic and solar activities. 
$2.048 \mathrm{~s} \times 19.51 \mathrm{~Hz}$ ) allows the recording of ionospheric components like the hiss, chorus, and whistlers, and the transmitter artificial signals. We use the so-called survey mode, which allows the recording of low bit-rate data all around the Earth at invariant latitudes $<65^{\circ}$. We center our attention on the VLF signals associated with four transmitters: (a) the NWC transmitter (Australia: latitude $=-21.5^{\circ}$, longitude $=114^{\circ}$ ), the FTU transmitter (France: latitude $=+46.4^{\circ}$, longitude $=1.05^{\circ}$ ), the JP transmitter (Japan: latitude $=+32^{\circ}$, longitude $=130^{\circ}$ ) and the DFY transmitter $\left(\right.$ Germany: latitude $=+52.5^{\circ}$, longitude $\left.=13.5^{\circ}\right)$. We select the DEMETER orbits during periods where this micro-satellite was above the transmitter station. A 'rectangle' area centered on the VLF transmitter station is selected, with latitude and longitude ranges of about $10^{\circ}$. This allows daily collected measurements of the ICE experiment for frequencies close to the VLF transmitter frequency. Table 1 lists the main features of the VLF stations and the closest frequencies to the transmitter.

\subsection{Solar and geomagnetic activities}

Figure 1 shows the variations of the daily Ap-index (upper panel) and the daily sunspot number (lower panel) versus the day of the year (DOY; starting from January 1, 2004). In each panel of Figure 1, the beginning and the end of the time intervals where the high activity was recorded are indicated by colored vertical dashed lines. This time interval corresponds to about several days, on average. Table 2 and Table 3 list the sunspot numbers associated with the solar activity, and the daily Ap-index linked to the geomagnetic activity, respectively. For each maximum of activity, Table 2 and Table 3 give: the observation date, the corresponding DOY, the Ap-index or the sunspot number,

\begin{tabular}{cccc}
\hline Date & Day of year & Daily sunspots & Significance \\
\hline 20041024 & 0298 & 099 & $\mathrm{a}$ \\
20050116 & 0382 & 065 & \\
20050511 & 0497 & 082 & \\
20050704 & 0551 & 107 & $\mathrm{~b}$ \\
20051203 & 0703 & 060 & $\mathrm{c}$ \\
20060406 & 0827 & 054 & $\mathrm{~d}$ \\
20061103 & 1038 & 044 & \\
\hline
\end{tabular}

Table 2. Sunspot numbers associated with the solar activity.

\begin{tabular}{cccc}
\hline Date & Day of year & Daily Ap index & Significance \\
\hline 20041110 & 0315 & 161 & $\mathrm{a}$ \\
20050110 & 0376 & 084 & \\
20050510 & 0494 & 091 & \\
20050810 & 0602 & 102 & $\mathrm{~b}$ \\
20060414 & 0835 & 065 & $\mathrm{c}$ \\
20061210 & 1080 & 094 & $\mathrm{~d}$ \\
\hline
\end{tabular}

Table 3. Daily Ap-index linked to the geomagnetic activity. and the probable common event. It is clear from Figure 1 that the decrease in the solar activity (minimum in June 2006) is followed by a decrease in the geomagnetic activity. Hence, events (a), (b), (c) and (d), as reported in Table 2 and Table 3 , are probably correlated with a time delay of about 17 days, 51 days, 8 days and 42 days, respectively. The other events show first the growth of the geomagnetic activity, followed by the increase in the solar activity. Selected periods are used to study the presence, or not, of any correlation between these activities and the VLF flux density linked to the ground-based transmitter signal.

\subsection{Correlations between the geomagnetic and solar activities} and the very low frequency transmitter signals

Figure 2 shows the variations in the VLF transmitter signals as recorded by the ICE experiment above the corresponding stations. We consider the period beginning on August 11, 2004, to December 31, 2006. The maximum VLF intensity is about $8 \times 10^{5} \mathrm{mV}^{2} \mathrm{~m}^{-2} \mathrm{~Hz}^{-1}$ for the NWC transmitter, $9 \times 10^{4} \mathrm{mV}^{2} \mathrm{~m}^{-2} \mathrm{~Hz}^{-1}$ for the FTU transmitter, $8 \times 10^{3} \mathrm{mV}^{2} \mathrm{~m}^{-2} \mathrm{~Hz}^{-1}$ for the JP transmitter, and $3 \times 10^{3} \mathrm{mV}^{2}$ $\mathrm{m}^{-2} \mathrm{~Hz}^{-1}$ for the DFY transmitter. The NWC transmitter is remarkably intense when it is compared to the others, e.g. it is two orders of magnitude more intense than the DFY transmitter. We note the presence of gaps in the data, because the ICE experiment was not operating or the transmitter was stopped. For example, the common gap of about 23 days for all of the stations between September 27, 2005 (DOY 616 in Figure 2) and October 19, 2005 (DOY 659 in Figure 2) is due to the absence of observations for the DEMETER satellite. Sometimes the transmitter was not in operation, as seen in Figure 2, where the VLF signals from the other transmitters were recorded. We correlated the VLF transmitter signals with the selected periods of solar and geomagnetic activities, as reported in Table 2 and Table 3, respectively. For this, we used a routine written in the Interactive Data Language (IDL) software, that allows the estimation of the degree of correlation and the corresponding lag. The formula is:

$$
P_{x y}(L)=\left\{\begin{array}{l}
\frac{\sum_{k=0}^{N-|L|-1}\left(x_{k+|L|}-\bar{x}\right)\left(y_{k}-\bar{y}\right)}{\sqrt{\left[\sum_{k=0}^{N-1}\left(x_{k}-\bar{x}\right)^{2}\right]\left[\sum_{k=0}^{N-1}\left(y_{k}-\bar{y}\right)^{2}\right]}} \text { for } L<0 \\
\frac{\sum_{k=0}^{N-L-1}\left(x_{k}-\bar{x}\right)\left(y_{k+L}-\bar{y}\right)}{\sqrt{\left[\sum_{k=0}^{N-1}\left(x_{k}-\bar{x}\right)^{2}\right]\left[\sum_{k=0}^{N-1}\left(y_{k}-\bar{y}\right)^{2}\right]}} \text { for } L \geq 0
\end{array}\right.
$$

This function $\mathrm{P}_{\mathrm{xy}}(\mathrm{L})$ computes the cross-correlation of two sample populations $\mathrm{X}$ and $\mathrm{Y}$ as a function of the lag $\mathrm{L}$. In this case, $\bar{x}$ and $\bar{y}$ are the means of the sample populations $\mathrm{x}=$ $=\left(\mathrm{x}_{0}, \mathrm{x}_{1}, \mathrm{x}_{2}, \ldots, \mathrm{x}_{\mathrm{N}-1}\right)$ and $\mathrm{y}=\left(\mathrm{y}_{0}, \mathrm{y}_{1}, \mathrm{y}_{2}, \ldots, \mathrm{y}_{\mathrm{N}-1}\right)$, respectively 

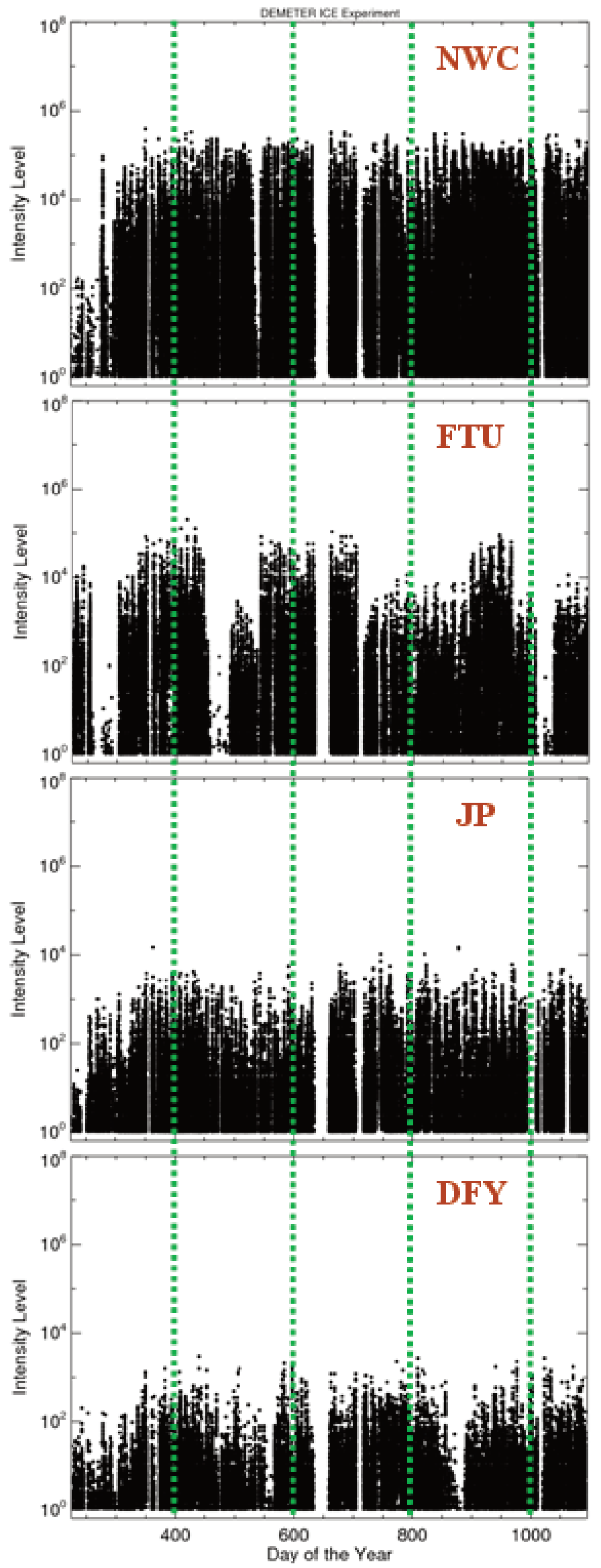

Figure 2. Flux density variations versus the DOY for the VLF transmitter stations in Australia (NWC, top panel), France (FTU, second panel), Japan (JP, third panel), and Germany (DFY, bottom panel).

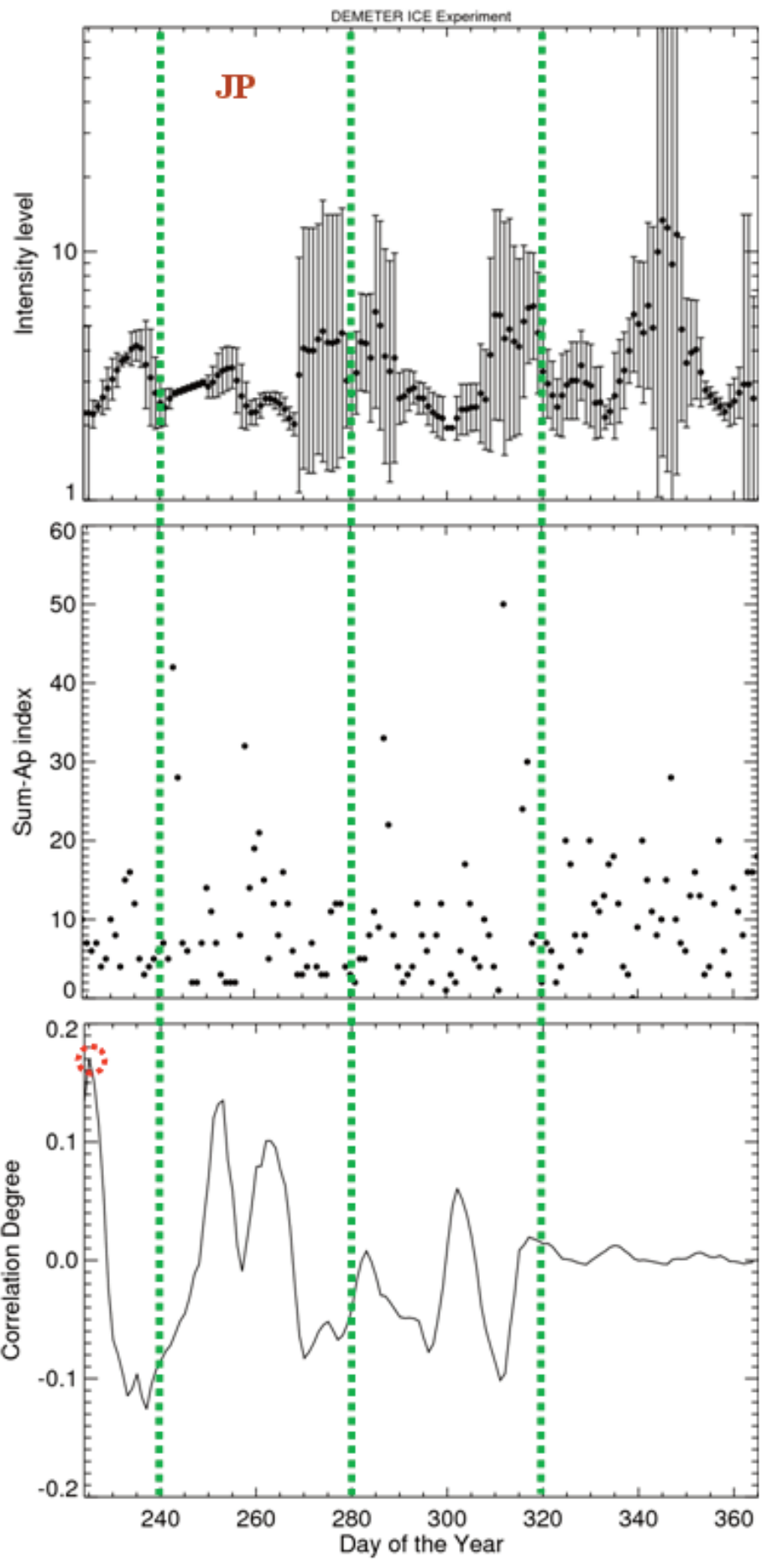

Figure 3. The VLF transmitter signals (top panel) and the daily Ap-index (second panel) and their estimated degree of correlation (bottom panel). The degree of correlation is about $15 \%$, with a lag of $<1$ day.

[Fuller 1976]. Figure 3 shows the procedure to estimate the degree of correlation. We used two sets of data, one from the JP transmitter, and the other from the daily Ap-index, for the same period from August 24, 2004 (DOY 237) to December 26, 2004 (DOY 306). Figure 3 shows the averaged transmitter signal of the JP signal (first panel), the daily Apindex (second panel), and the degree of correlation (third panel). In this example, the degree of correlation is about 


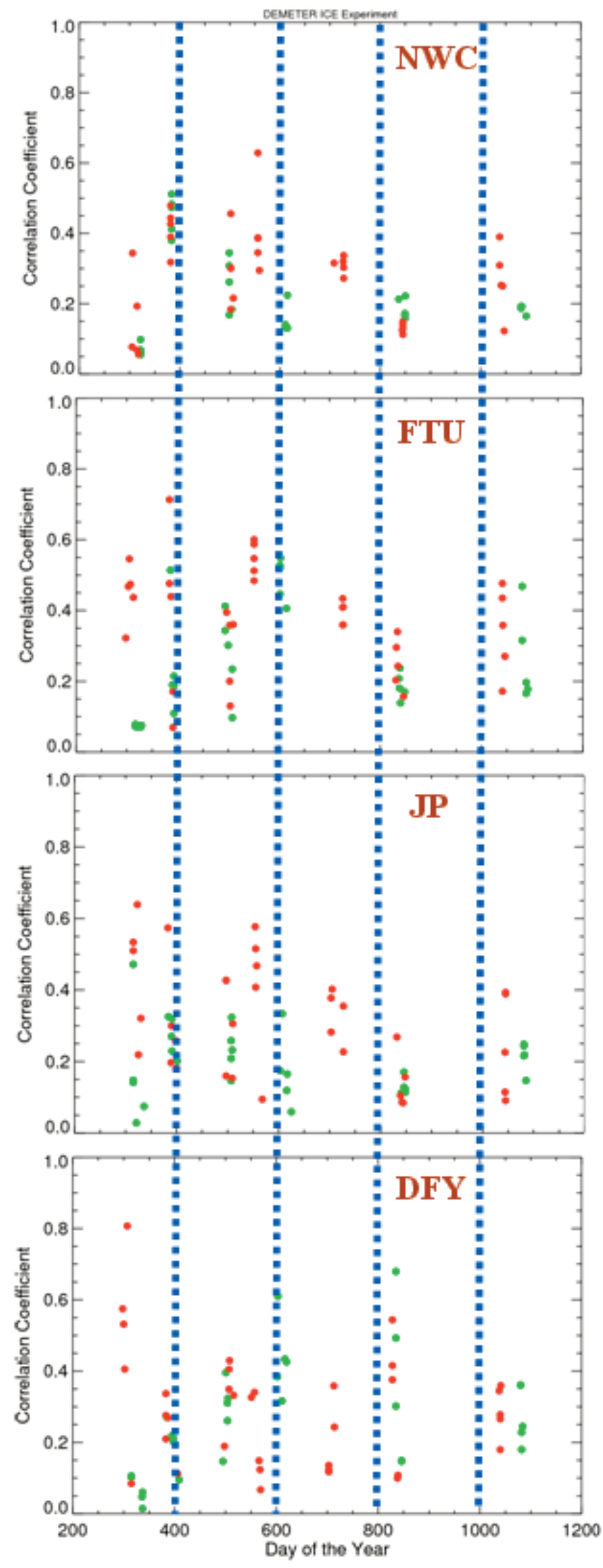

Figure 4. Variations in the degree of correlations versus the DOY. The $\mathrm{red} /$ green circles correspond to the degrees of correlations between the sunspot/Ap-index and the VLF transmitter signals, for the Australia (NWC, top panel), France (FTU, second panel), Japan (JP, third panel) and Germany (DFY, bottom panel)
$15 \%$, with a time lag of less than one day. In the correlation processes, we consider three different signal-to-noise ratios of 1.0,10 and 100 [Schroeder 2000]. The aim is to determine the dependence, or not, of the correlation on the signal-tonoise ratio. The results are shown in Figure 4, where the green and red indicate the correlation of the VLF signal with the geomagnetic and solar activities, respectively. First, the correlation is, on average, $<40 \%$ for all of the stations. Secondly, the solar activity might have a more important effect on the VLF transmitter signal than the geomagnetic activity. Thirdly, the variations in the correlation coefficients versus the DOY are similar for all of the stations. Hence a decrease in the correlation from August 2004 (coefficient of correlation of about 50\%) to November 2005 (coefficient of correlation of about $20 \%$ ) is evident when combining all of the stations. Fourthly, only in one case is the degree of correlation in the order of $80 \%$, as shown in the fourth panel of Figure 4 (i.e. for the DFY transmitter).

\section{Discussion and conclusions}

We studied the variations in the VLF transmitter signals recorded by the ICE experiment on the DEMETER microsatellite. The orbital features allowed us to cover a time interval of about 40 min for all longitudes and the invariant latitude range between $-65^{\circ}$ and $+65^{\circ}$. The subsequent analysis investigates the influence of the solar and geomagnetic activities on the reception of the VLF transmitter by the DEMETER micro-satellite. In the following, we discuss our main results: (a) the influence of the solar and geomagnetic activities on the detection, or not, of precursor electromagnetic emissions; and (b) the way to explain how the VLF signal is disturbed along its path to the satellite.

\subsection{Effects of the solar and geomagnetic activities on the} transmitter signals

We considered here a period of investigation over more than two years. This allows us to select different time intervals where we can note enhancements of the geomagnetic and solar activities. We have estimated the degree of correlation for four VLF transmitter stations. The correlation was, on average, about $40 \%$. As shown in Figure 1 , the Ap index and the sunspot number reached over 100 during these strong geomagnetic and solar activities. The effects of these activities can be considered in the analysis of the pre-seismic precursors, although it is still not dominant. This effect can be neglected when the daily Ap-index or sunspot number is $<20$. Also, we see that the control of the solar activity is usually dominant when it is compared with the geomagnetic activity. This result is interesting, because it shows that ionization of the $\mathrm{D}$ - and E-layers of the ionosphere disturbs the path where the VLF transmitter signals propagate in particular under the effects of the Sun. 
In the literature, the investigations of pre-seismic ionospheric anomalies mainly report parameters that are related to the geomagnetic activity (like the Ap-index or Dst-index), and only a few investigations have analyzed solar activity effects [e.g. Liperovskaya et al. 2008]. However, we show in our studies that both can be considered to estimate their effects on the ionosphere.

\subsection{Lithosphere-atmosphere-ionosphere coupling}

The low degree of correlation $(<40 \%)$ allows us to conclude that the drop in the VLF transmitter over seismic regions, as reported in several studies, might be related to the preparatory zone. The model proposed by Liperovsky et al. [2000] and Molchanov [2004] might explain how the gaswater release from the earthquake preparatory zone can disturb the ionosphere. These studies showed that an upward energy flux of atmospheric gravity waves can disturb the ionospheric electron density above seismic regions. A recent study of Stangl et al. [2011] found that for the L'Aquila earthquake, there was anomaly enhancements in the Total Electron Content (TEC) measurements. In a quasi-similar time interval, a drop in the intensity of the VLF electric field occurs. This study concluded that the paths of the VLF signals are deviated during their propagation in the turbulent ionosphere. The VLF signals drop because they only occasionally reach the DEMETER satellite. Other models have suggested that the ionospheric disturbances are linked to the changes in the atmospheric electricity (conductivity and vertical field) due to air ionization produced by radon released from an active tectonic fault before an earthquake. Space observations have reported electric fields of about 3 $\mathrm{mV} / \mathrm{m}$ to $7 \mathrm{mV} / \mathrm{m}$ [Yokoyama et al. 2002, Chmyrev et al. 1989]. However, Liperovsky et al. [2005, 2008b] showed an electric field of the order of $1000 \mathrm{~V} / \mathrm{m}$. Recent investigations of Ampferer et al. [2010] and Denisenko et al. [2008] proposed much lower fields at the ionosphere level. This suggests that a further comparison of models and observations is recommended for the prediction of preseismic electromagnetic phenomena.

Acknowledgements. The authors acknowledge Centre National d'Etudes Spatiales (CNES) for the use of the DEMETER data, and they thank Jean-Jacques Berthelier, who provided the data from the electric field experiment (Instrument Champ Electrique - ICE).

\section{References}

Ampferer, M., V.V. Denisenko, W. Hausleitner, S. Krauss, G. Stangl, M. Y. Boudjada and H. K. Biernat (2010). Decrease of the electric field penetration into the ionosphere due to low conductivity at the near ground atmospheric layer, Ann. Geophys., 28, 779-787.

Berthelier, J.J., M. Godefroy, F. Leblanc, M. Malingre, M. Menvielle, D. Lagoutte, J. Y. Brochot, F. Colin, F. Elie, C.
Legendre, P. Zamora, D. Benoist, Y. Chapuis, J. Artru and R. Pfaff (2006). ICE, the electric field experiment on DEMETER, Planet. Space Sci., 54, 456-471.

Biagi, P.F. and M. Hayakawa (2002). Possible premonitory behaviour of LF radiowaves on the occasion of the Slovenia earthquakes ( $M=5.2-6.0-5.1)$ occurred on March-May 1998, In: Seismo-Electromagnetics: Lithosphere-Atmosphere-Ionosphere Coupling, edited by M. Hayakawa and O. Molchanov, TERRAPUB, Tokyo, 249-253.

Boudjada, M.Y., K. Schwingenschuh, R. Döller, A. Rozhnoi, M.Parrot, P.F. Biagi, P.H. M. Galopeau, M. Solovieva, O. Molchanov, H.K. Biernat, G. Stangl, H. Lammer, I. Moldovan, W. Voller and M. Ampferer (2010). Decrease of VLF transmitter signal and Choruswhistler waves before l'Aquila earthquake occurrence, Nat. Hazards Earth Sys., 10, 1487-1494; doi: 10.5194/ nhess-10-1487-2010.

Boudjada, M.Y., K. Schwingenschuh, H.K. Biernat, J.J. Berthelier, J. Blecki, M. Parrot, M. Stachel, Ö. Aydogar, G. Stangl and J. Weingrill (2008). Similar behaviors of natural ELF/VLF ionospheric emissions and transmitter signals over seismic Adriatic regions, Nat. Hazards Earth Sys., 8, 1229-1236; doi:10.5194/nhess-8-12292008.

Chmyrev, V.M., N.V. Isaev, S.V. Bilichenko and G. Stanev (1989). Observation by space-borne detectors of electric fields and hydro-magnetic waves in the ionosphere over an earthquake Centre, Phys. Earth Planet., 57, 110114.

Denisenko, V.V., M.Y. Boudjada, M. Horn, E.V. Pomozov, H.K. Biernat, K. Schwingenschuh, H. Lammer, G. Prattes and E. Cristea (2008). Ionospheric conductivity effects on electrostatic field penetration into the ionosphere, Nat. Hazards Earth Sys., 8, 1009-1017,.

Fraser-Smith, A.C., A. Bernardy, P.R. McGill, M.E. Ladd, R.A. Helliwell and O.G. Villard Jr. (1990). Low frequency magnetic field measurements near the epicenter of the Ms 7.1 Loma Prieta earthquake, Geophys. Res. Lett., 17, 1465-1468.

Fuller, W.A. (19769. Introduction to statistical time series, John Wiley, New York.

Gokhberg, M.B., V.A. Morgunov, T. Yoshino and I. Tomizawa (1982). Experimental measurement of electromagnetic emissions possibly related to earthquakes in Japan, J. Geophys. Res., 87, 824-828.

Hayakawa, M. and O.A. Molchanov (2002). Seismo Electromagnetics: Lithosphere-Atmosphere-Ionosphere Coupling, Terra Scientific Publishing Company (TERRAPUB), Tokyo.

Hayakawa, M., R. Kawate, O.A. Molchanov and K. Yumoto (1996). Results of ultra-low-frequency magnetic field measurements during the Guam earthquake of $8 \mathrm{Au}$ gust 1993, Geophys. Res. Lett., 23, 241-244. 
Liperovskaya, E.V., P.-F. Biagi, C.-V. Meister and M.V. Rodkin (2008). foF2 seismo-ionospheric effect analysis: actual data and numerical simulations, Nat. Hazards Earth Sys., 8, 1387-1393.

Liperovsky, V.A., O.A. Pokhotelov, E.V. Liperovskaya, M. Parrot, C.-V. Meister and O.A. Alimov (2000): Modification of sporadic E-layers caused by seismic activity, Surv. Geophys., 21, 449-486.

Liperovsky, V.A., C.-V. Meister, E.V. Liperovskaya, V.F. Davidov and V.V. Bogdanov (2005). On the possible influence of radon and aerosol injection into the atmosphere and ionosphere before earthquakes, Nat. Hazards Earth Sys., 5, 783-789.

Liperovsky, V.A., O.A. Pokhotelov, C.V. Meister and E.V. Liperovskaya (2008a). Physical models of coupling in the lithosphere-atmosphere-ionosphere system before earthquakes, Geomagn. Aeron., 48 (6), 795-806.

Liperovsky, V.A., C.-V. Meister, E.V. Liperovskaya and V.V. Bogdanov (2008b). On the generation of electric field and infrared radiation in aerosol clouds due to radon emanation in the atmosphere before earthquakes, Nat. Hazards Earth Sys., 8, 1199-1205.

Molchanov, O.A., Y. A. Kopytenko, P.M. Voronov, E.A. Kopytenko, T.G. Matiashvili, A.C. Fraser-Smith and A. Bernardy (1992). Results of ULF magnetic field measurements near the epicenters of the Spitak $(\mathrm{Ms}=6.9)$ and Loma Prieta (Ms=7.1)earthquakes: comparative analysis, Geophys. Res. Lett., 19, 1495-1498.

Molchanov, O.A. (2004). On the origin of low- and middlelatitude ionospheric turbulence, Phys. Chem. Earth, 29, 559-567, 2004.

Molchanov, O.A., A. Rozhnoi, M. Solovieva, O. Akentieva, J.J. Berthelier, M. Parrot, F. Lefeuvre, P.F. Biagi, L. Castellana and M. Hayakawa (2006). Global diagnostics of the ionospheric perturbations related to the seismic activity using the VLF radio signals collected on the DEMETER satellite, Nat. Hazards Earth Sys., 6, 745-753,

Molchanov, O.A. and M. Hayakawa (2008). Seismo-electromagnetics and related phenomena: History and latest results, TERRAPUB, Tokyo.

Muto, F., M. Yoshida, T. Horie, M. Hayakawa, M. Parrot and O.A. Molchanov (2008). Detection of ionospheric perturbations associated with Japanese earthquakes on the basis of reception of LF transmitter signals on the satellite DEMETER, Nat. Hazards Earth Sys., 8, 135141; doi: 10.5194/nhess-8-135-2008.

Parrot, M. (1995). Electromagnetic noise due to earthquakes, in: Handbook of Atmospheric Electrodynamics, edited by H. Volland, CRC Press, Boca Raton, FL, vol. II, 95-116.

Parrot, M. and F. Lefeuvre (1985). Correlation between GEOS VLF emissions and earthquakes, Ann. Geophys., 3, 737-748, http: / / www.ann-geophys.net/3/737/1985/.
Parrot, M., D. Benoist, JJ. Berthelier, J. Blecki, Y. Chapuis, F. Colin, F. Elie, P. Fergeau, D. Lagoutte, F. Lefeuvre, C. Legendre, M. Leveque, J.L. Pincon, B. Poirier, H.C. Serana and P. Zamora (2006). The magnetic field experiment IMSC and its data processing onboard DEMETER: Scientific objectives, description and first results, Planet. Space Sci., 54, 441-455.

Pulinets, S.A., K.A. Boyarchuk, V.V. Hegai and A.V. Karelin (2002). Conception and model of seismo-ionospheremagnetosphere coupling, In: Seismo-Electromagnetics: Lithosphere-Atmosphere-Ionosphere Coupling, edited by M. Hayakawa and O.A. Molchanov, TERRAPUB, Tokyo, 353-361.

Rozhnoi, A., O.A. Molchanov, M. Solovieva, V. Gladyshev, O. Akentieva, J.J. Berthelier, M. Parrot, F. Lefeuvre, M. Hayakawa, L. Castellana and P.F. Biagi (2007). Possible seismo-ionosphere perturbations revealed by VLF signals collected on ground and on a satellite, Nat. Hazards Earth Sys., 7, 617-624, http://www.nat-hazards-earthsyst-ci.net/7/617/2007/.

Schroeder, D.J. (2000). Astronomical Optics, Academic Press, London.

Slominska, E., J. Blecki, M. Parrot and J. Slominski (2008). Satellite study of VLF ground-based transmitter signals during seismic activity in Honshu Island, Physics and Chemistry of the Earth, Phys. Chem. Earth, Parts A/B/C; doi: 10.1016/j.pce.2008.06.016.

Stangl, G., M.Y. Boudjada, P.F. Biagi, S. Krauss, A. Maier, K. Schwingenschuh, E. Al-Haddad, M. Parrot and W. Voller (2011). Investigation of TEC and VLF space measurements associated to L'Aquila (Italy) earthquakes, Nat. Hazards Earth Sys., 11, 1019-1024.

Yokoyama, T., M. Yamamoto, R.F. Pfaff, S. Fukao and N. Iwagami (2002). SEEK-2 campaign measurement of the electric field in the E-region and its association with the QP echoes, In: Abstracts for the 112th SGEPSS Fall Meeting, University of Electro-Communications, Tokyo, 12-13.

Warwick, J.W., C. Stoker and T.R. Meyer (1982). Radio emission associated with rock fracture: possible application to the great Chilean earthquake of 22 May 1960, J. Geophys. Res., 87, 2851-2859.

\footnotetext{
${ }^{\star}$ Corresponding author: Mohammed Yahia Boudjada, Space Research Institute, Austrian Academy of Sciences, Graz, Austria; email: mohammed.boudjada@oeaw.ac.at.
}

(C) 2012 by the Istituto Nazionale di Geofisica e Vulcanologia. All rights reserved. 